\title{
Dimensional Analysis of Airline Quality
}

\author{
Everette S. Gardner, Jr., Ph.D. \\ Decision and Information Sciences Department \\ C. T. Bauer College of Business \\ University of Houston \\ 4800 Calhoun \\ Houston, Texas 77204-6021 \\ Telephone 713-743-4720 \\ egardner@uh.edu
}

November 7, 2003 


\section{Dimensional Analysis of Airline Quality}

Dimensional analysis is widely used in physics and engineering to contribute to the modeling of systems in which variables are measured in incompatible units. I used dimensional analysis to rank the airlines in overall quality based on U.S. Department of Transportation data: on-time arrivals, denied boardings, mishandled baggage, and customer complaints. The results conflict with the well known Airline Quality Rating (AQR), published since 1991. Weighted averages of quality data in the AQR are dimensionally incorrect and produce illogical rankings that are virtually independent of on-time arrivals. For example, the 2001 AQR ranks Alaska Airlines first in overall quality, despite the worst on-time performance in the industry. Dimensional analysis places Alaska Airlines near the bottom of the industry, seventh in overall quality. 


\section{Dimensional Analysis of Airline Quality}

\section{Introduction}

In physics and engineering, dimensional analysis is a standard methodology for reducing physical properties such as energy and acceleration to their fundamental dimensions of length, mass, and time. In general, dimensional analysis facilitates mathematical modeling, usually by reducing the number of variables, and avoids the nuisance of incompatible units. For example, acceleration is expressed via dimensional analysis as length or distance per unit of time squared. Whether distance is measured in English or metric units does not matter.

In operations research, Epstein (1957) appears to have been the first to recognize the value of dimensional analysis. He presented a general procedure, based on Bridgman's (1922) tutorial for physicists, for computing dimensionless indices to assist in choosing between competing engineering designs. Naddor (1966) demonstrated that dimensional analysis can simplify solutions and assist in interpreting the behavior of queuing, inventory lot-sizing, and linear programming models. Since Naddor's work appeared, there have been only a few published applications of dimensional analysis in operations research. These include inventory modeling (Sivazlian, 1971; Ehrhardt, 1979; Silver, 1983; Ehrhardt and Mosier, 1984; Vignaux and Jain, 1988), warehouse layout (Mahoney and Ventura, 1985), logistics networks (Daganzo, 1987), facility location (Starr, 1996), supplier 
performance evaluation (Willis, Huston, and Pohlkamp, 1993; Li, Fun, and Hung, 1997), and selection of industrial robots (Braglia and Gabbrielli, 2000).

It is unfortunate that more operations researchers are not aware of dimensional analysis. Huntley (1951) lists a number of ways that dimensional analysis can serve the physicist as an analytical tool. They are repeated here because they apply to operations research as well:

1. In aiding the memory to reconstitute forgotten formulae and equations.

2. In checking algebraic errors, which are revealed by the lack of dimensional homogeneity of equations.

3. In providing a conversion factor for changing from one system of units to another.

4. In interpreting the behavior of scale models and capitalizing the information gained from them.

5. In guiding the experimenter in the selection of experiments capable of yielding significant information, and in the avoidance of redundant experiments.

6. In obtaining partial solutions of problems too complex for ordinary mathematical analysis.

This paper demonstrates several of Huntley's points in applying dimensional analysis to the evaluation of airline quality. The results differ substantially from the Airline Quality Rating (AQR), published annually since 1991 by Bowen and Headley (2003). The AQR ranks U.S. domestic airlines in overall quality using weighted averages of various data published by the U.S. Department of Transportation (DOT). Since its inception, the AQR annual report has received a great deal of attention in the news media. For examples, see Bowen and 
Headley (2003), who list television programs, newspapers, and magazines that have featured the AQR. In the airline industry, the AQR appears to be generally accepted judging from the awards its authors have received from organizations such as the American Institute of Aeronautics and Astronautics and the Travel and Transportation Research Association.

The AQR weighted averages are shown to be dimensionally incorrect (see Huntley's second point above) and seriously misleading. To illustrate the problem, using Naddor's (1966) notation, let [A] represent the dimension of some quantity A. If $A+B=C$, then $[A]=[B]=[C]$. This rule is referred to as dimensional homogeneity, that is "it makes no sense to add apples and oranges," which is precisely the problem with the AQR. The AQR overall quality rating is the sum of a percentage of on-time arrivals, a rate of mishandled bags per 1,000 passengers, a rate of denied boardings per 10,000 , and a rate of customer complaints per 100,000 .

Perhaps the most bizarre airline rankings occurred in 2001, when Bowen and Headley placed Alaska Airlines first in overall quality despite an on-time arrival rate of $69 \%$, the worst in the industry. This paper corrects the defects in the AQR by developing a dimensionless value function for ranking the airlines. The 2001 results place Alaska Airlines near the bottom of the industry, seventh in overall quality. 


\section{Department of Transportation Airline Quality Data}

From 1991 - 1997, the AQR was based on a weighted average of nineteen quality factors collected from the National Transportation Safety Board, the Federal Aviation Administration, and other sources within the DOT (Bowen and Headley, 2003). The relationship to quality of many of these factors was unclear from the viewpoint of the customer. Examples were corporate bond ratings, average seat-mile cost, and number of aircraft in the carriers' fleets. Beginning with 1998 data, Bowen and Headley simplified the weighted average to include only four quality factors: on-time arrivals, involuntary denied boardings, mishandled baggage, and customer complaints. These factors are listed in Table 1 for 1998 - 2002. I did not reexamine the data for 1991 - 1997 because I did not believe that models including so many dubious quality measures would produce meaningful results. Another consideration is that I could not confirm all of the DOT data for the earlier years.

All data in Table 1 are taken from the DOT's Air Travel Consumer Reports (2003) for the U.S. carriers that have at least one percent of total domestic scheduled-service passenger revenues. The on-time arrival percentage covers nonstop flights between points within the United States. Flights are considered on time if they arrive at the gate within 15 minutes of scheduled times shown in the carriers' Computerized Reservations Systems. Canceled and diverted flights are counted as late. 


\begin{tabular}{|c|c|c|c|c|c|c|c|}
\hline & \multirow[b]{3}{*}{ Airline } & & & \multicolumn{4}{|c|}{ DOT Statistics } \\
\hline & & \multicolumn{2}{|c|}{ Overall rank } & \multirow{2}{*}{$\begin{array}{l}\text { On-Time } \\
\text { Arrival \% }\end{array}$} & \multirow{2}{*}{$\begin{array}{c}\text { Denied } \\
\text { Boardings }\end{array}$} & \multirow{2}{*}{$\begin{array}{c}\text { Mishandled } \\
\text { Bagqage }\end{array}$} & \multirow{2}{*}{$\begin{array}{l}\text { Customer } \\
\text { Complaints }\end{array}$} \\
\hline & & AQR & Dim. Anal. & & & & \\
\hline \multirow[t]{10}{*}{1998} & $\overline{\text { Alaska }}$ & 8 & 8 & 0.72 & 1.30 & 7.27 & 0.54 \\
\hline & America West & 6 & 9 & 0.69 & 1.14 & 3.88 & 2.11 \\
\hline & American & 3 & 4 & 0.80 & 0.46 & 4.40 & 1.14 \\
\hline & Continental & 2 & 1 & 0.77 & 0.14 & 4.06 & 1.02 \\
\hline & Delta & 4 & 5 & 0.80 & 1.31 & 4.27 & 0.79 \\
\hline & Northwest & 9 & 6 & 0.71 & 0.30 & 6.63 & 2.21 \\
\hline & Southwest & 5 & 3 & 0.81 & 1.73 & 4.53 & 0.25 \\
\hline & TWA & 7 & 10 & 0.78 & 2.61 & 5.39 & 1.29 \\
\hline & United & 10 & 7 & 0.74 & 0.57 & 7.79 & 1.28 \\
\hline & US Airways & 1 & 2 & 0.79 & 0.22 & 4.09 & 0.84 \\
\hline \multirow[t]{10}{*}{1999} & Alaska & 5 & 6 & 0.71 & 0.91 & 5.75 & 1.64 \\
\hline & America West & 8 & 10 & 0.70 & 1.39 & 4.52 & 3.73 \\
\hline & American & 7 & 4 & 0.74 & 0.43 & 5.21 & 3.50 \\
\hline & Continental & 2 & 3 & 0.77 & 0.34 & 4.42 & 2.62 \\
\hline & Delta & 3 & 8 & 0.78 & 1.53 & 4.39 & 1.82 \\
\hline & Northwest & 4 & 1 & 0.80 & 0.18 & 4.81 & 2.93 \\
\hline & Southwest & 1 & 2 & 0.80 & 1.38 & 4.22 & 0.40 \\
\hline & TWA & 9 & 7 & 0.81 & 0.73 & 5.38 & 3.45 \\
\hline & United & 10 & 9 & 0.74 & 0.90 & 7.01 & 2.66 \\
\hline & US Airways & 6 & 5 & 0.71 & 0.52 & 5.08 & 3.15 \\
\hline \multirow[t]{10}{*}{2000} & Alaska & 2 & 6 & 0.68 & 1.41 & 3.48 & 2.04 \\
\hline & America West & 10 & 10 & 0.66 & 1.12 & 6.62 & 7.51 \\
\hline & American & 6 & 4 & 0.73 & 0.42 & 5.50 & 3.54 \\
\hline & Continental & 7 & 7 & 0.78 & 1.80 & 5.35 & 2.84 \\
\hline & Delta & 1 & 1 & 0.75 & 0.33 & 4.49 & 2.01 \\
\hline & Northwest & 5 & 3 & 0.77 & 0.57 & 5.24 & 2.61 \\
\hline & Southwest & 3 & 2 & 0.75 & 1.89 & 5.00 & 0.47 \\
\hline & TWA & 8 & 8 & 0.77 & 2.54 & 6.06 & 3.47 \\
\hline & United & 9 & 9 & 0.61 & 1.43 & 6.57 & 5.30 \\
\hline & US Airways & 4 & 5 & 0.72 & 0.65 & 4.76 & 2.59 \\
\hline \multirow[t]{11}{*}{2001} & Alaska & 1 & 7 & 0.69 & 1.36 & 3.00 & 1.27 \\
\hline & America West & 7 & 5 & 0.75 & 0.38 & 4.22 & 3.72 \\
\hline & American & 6 & 4 & 0.76 & 0.36 & 4.60 & 2.51 \\
\hline & American Eagle & 10 & 6 & 0.71 & 0.43 & 7.36 & 1.70 \\
\hline & Continental & 8 & 9 & 0.81 & 1.51 & 4.29 & 2.23 \\
\hline & Delta & 5 & 8 & 0.78 & 0.77 & 4.11 & 2.16 \\
\hline & Northwest & 3 & 3 & 0.80 & 0.45 & 4.19 & 1.97 \\
\hline & Southwest & 4 & 2 & 0.82 & 1.50 & 4.77 & 0.38 \\
\hline & TWA & 11 & 11 & 0.81 & 1.83 & 6.35 & 2.54 \\
\hline & United & 9 & 10 & 0.74 & 0.92 & 5.07 & 3.24 \\
\hline & US Airways & 2 & 1 & 0.78 & 0.34 & 3.86 & 1.87 \\
\hline \multirow[t]{11}{*}{2002} & Alaska & 2 & 6 & 0.78 & 1.17 & 2.63 & 0.91 \\
\hline & America West & 4 & 1 & 0.83 & 0.20 & 3.55 & 1.63 \\
\hline & American & 6 & 5 & 0.84 & 0.31 & 4.27 & 1.29 \\
\hline & American Eagle & 10 & 3 & 0.79 & 0.19 & 9.81 & 0.60 \\
\hline & Continental & 5 & 7 & 0.84 & 0.87 & 3.14 & 1.41 \\
\hline & Delta & 7 & 10 & 0.80 & 1.11 & 3.57 & 1.37 \\
\hline & Northwest & 9 & 8 & 0.81 & 0.60 & 4.52 & 1.45 \\
\hline & Southwest & 3 & 4 & 0.83 & 1.09 & 3.52 & 0.33 \\
\hline & United & 8 & 9 & 0.84 & 0.69 & 3.76 & 1.71 \\
\hline & US Airways & 1 & 2 & 0.83 & 0.35 & 2.95 & 1.13 \\
\hline & AQR Weight & & & 8.63 & -8.03 & -7.92 & -7.17 \\
\hline
\end{tabular}

Table 1. The Airline Quality Rating (AQR) ranks airlines using weighted averages of four DOT quality factors. The averages are dimensionally incorrect because the data are measured on four different scales. Alternative rankings are based on dimensional analysis, a method of combining multiple criteria into a single performance measure. The rankings are often considerably different. 
On-time arrival performance has always been controversial because the numbers can be biased by air traffic control policies and the geographic regions in which an airline's flights are concentrated. The numbers are also difficult to interpret because there is little public information on the specific causes of delays and cancellations. In hopes of providing more useful reports, the DOT required carriers to collect the causes of airline cancellations and delays (DOT, 2002) starting in June, 2003. The new rules create four broad categories for reporting the causes of cancellations: (1) circumstances within the control of the carrier, (2) extreme weather, (3) security, and (4) a catch-all "National Aviation System" category, including non-extreme weather, airport operations, heavy traffic volume, and air-traffic control. Delays are reported in the same way except that an additional category collects data on delays due to late incoming aircraft from a previous flight. The new rules were imposed over the opposition of the industry trade group, the Air Transport Association, which believes that causal data are proprietary and should only be released to the public in aggregate form, with no identification of individual carriers.

The second quality factor, involuntary denied boardings, is the number of passengers per 10,000 who hold confirmed reservations and are denied boarding ("bumped") from flights because they are oversold. Cancelled, delayed, or diverted flights are not counted in denied boardings. Flights include both domestic and international flight segments that originate in the United States. Many involuntary denied boardings are actually voluntary because the DOT counts passengers who volunteer to take other flights in return for compensation. There 
are no public data on the number of passengers who receive compensation although the practice is common in the industry. Another problem in denied boardings data is that the DOT counts passengers who purchased discounted tickets that specifically rule out compensation for denied boardings.

Mishandled bags are the number of enplaned passengers per 1,000 who report loss, damage, delay, or pilferage. The figures include all such reports, regardless of whether bags were ultimately found in good condition or passengers were subsequently compensated. The validity of mishandled baggage reports is not considered in reporting.

Finally, customer complaints are the number of passengers per 100,000 who file complaints with the DOT. About $24 \%$ of the complaints in 2002 were caused by cancellations, delays, or other deviations from flight schedules. Another 19\% were about customer service in general with no further explanation. About $16 \%$ dealt with oversales, reservations, ticketing, and boarding, and 14\% dealt with baggage handling. Remaining complaints included a host of miscellaneous problems. Safety issues are excluded from customer complaints because they are referred to the Federal Aviation Administration.

In most industries, customer complaints are the most important quality measure. For an excellent discussion of the importance of complaint data and how it should be used in quality management, see Evans and Lindsay (2002). In the airline industry, my opinion is that customer complaint data are the least important of the DOT quality measures. The proportion of customers who complain is so small and oddly distributed over time that it is difficult to accept that 
complaints are in any sense representative of the population of airline passengers. In 2002, there were more than 510 million enplanements (for the ten airlines listed in Table 1) but only 6,229 customers complained to the DOT. Thus one in 82,000 customers complained, compared to an average rate of one in 25 customers in other industries (Evans and Lindsay, 2002). It seems likely that most complaints are made directly to the airlines rather than the DOT, but there is no public information on direct complaints. Within the tiny sample of those who did complain to the DOT, there is much double-counting. Most baggage complaints relate to problems already counted in the rate of mishandled baggage, while most complaints about oversales are duplicated in the rate for involuntary denied boardings.

The terrorist attacks certainly distorted DOT data from September December, 2001, although adjustments in DOT reports are inconsistent. For example, the on-time arrival report for the month of September excludes 11 - 30 but the entire month was used in the final percentage for the year. Mishandled bags exclude September 11 - 30 both for the month and year. Denied boardings and customer complaints include all of September both for the month and year. The DOT receives most customer complaints via mail and there were substantial mail disruptions in the Washington, D.C. area due to the anthrax attacks during September - December, 2001. The number of complaints for this period was substantially lower than for the same period in 2000 , and it is not clear whether some airlines were affected disproportionately. Nevertheless, Bowen and Headley used the DOT data and I did the same for the sake of consistency in Table 1. 


\section{AQR Methodology}

The AQR (Bowen and Headley, 2003) is a weighted average of DOT quality data, with the weights derived from a survey of 65 airline industry experts regarding their opinion "as to what consumers would rate as important (on a scale of 1 to 10) in judging airline quality." The AQR documentation does not specify when this survey was taken but the weights have not been changed since at least 1995, the earliest AQR report I could find that contained detailed information on the computations.

Weights are given signs that reflect the "direction of impact that the criteria should have on the consumer's rating of airline quality." The on-time arrival weight (8.63) receives a positive sign, while all other weights are negative and similar in magnitude. Involuntary denied boardings are weighted at -8.03 , mishandled bags at -7.92 , and customer complaints at -7.17 . AQR reports do not disclose the identity of the experts, how they were selected, if they knew how their opinions would be used, or why experts rather than passengers themselves were surveyed to determine weights. Another reason to question the original survey is that absolute weights are so similar. If all weights are reset to unity (with signs retained), there is no significant difference in AQR rankings from 1998 - 2002.

The annual AQR quality rankings for 1998 - 2002 and the data behind them are shown in Table 1. Rankings are based on a weighted average of a percentage (on-time arrivals), a rate per 1,000 passengers (denied boardings), a rate per 10,000 passengers (mishandled baggage), and a rate per 100,000 
passengers (customer complaints). This jumble of dimensions often produces illogical rankings.

To illustrate, consider the 2001 AQR rankings, which were extremely controversial in the airline industry. The only quality factor in which Alaska Airlines led the industry was in the rate of mishandled bags. Alaska was last in on-time arrivals yet ranked first in AQR overall quality. How did this ranking come about? On-time arrivals in the AQR weighted average are fractional numbers less than one while the other numbers are much larger. Because the weights are almost equal, on-time arrivals are virtually irrelevant in average scores. Sensitivity analysis shows that Alaska Airlines' 2001 on-time arrivals could have fallen from $69 \%$ to $45 \%$ and it would still have ranked first in the AQR. Now suppose that all airlines except Alaska were never late, that is they achieved $100 \%$ on-time arrivals for all flights in 2001; if Alaska achieved only $69 \%$ on-time arrivals, it would still have been ranked first.

Similar results occur in the AQR rankings in other years. For example, in 2002, U.S. Airways ranked first in the AQR. This carrier's on-time arrivals could have fallen from $83.4 \%$ to $50 \%$ and it would still have ranked first. If all other carriers achieved $100 \%$ on-time arrivals for the entire year, U.S. Airways would still have ranked first with a rate of $83.4 \%$. 


\section{Dimensional analysis}

The analytical problem in ranking the airlines using DOT quality data appears to be complex at first glance although the solution is relatively simple. We must identify a special kind of function, a value function that combines measurements of multiple quality factors into a single index of overall performance. To prevent dimensional problems, the value function must satisfy the condition that the ratio of the numbers measuring any two examples of the same quality factor shall not depend on the size of the units in which the measurement was made. In the terminology of dimensional analysis, this condition is called the "absolute significance of relative magnitude" (Bridgman, 1922). For example, the statement that one airline has twice as many mishandled bags as another has absolute significance, independent of the units in which mishandled bags are stated. The condition of absolute significance of relative magnitude is essential to all scientific systems of measurement but is really nothing more than common sense. Surely any sound value function cannot depend on units of measure.

The condition restricts the form that the value function may take. In a comparison of any two airlines, it can be proven (see Appendix) that the required value function is a geometric weighted average defined as the product of quality measurements, with each measurement raised to an exponent equal to its weight. Only ratio-scale values may be used for both exponents and measurements. Exponents are positive for desirable quality factors and negative for undesirable factors. 
To construct a dimensionally correct quality ranking of the airlines, all that is necessary is to sort their value functions. A little algebra shows that an equivalent ranking occurs when the airlines are scored using a weighted average of the logarithms of the quality measures. More complex but equivalent value ranking procedures based on dimensional analysis are available in Willis, Huston, and Pohlkamp (1993) and Li, Fun, and Hung (1997).

To understand the implications of dimensional analysis, it is helpful to study the effects of rescaling the airline quality measurements. It seems that one way to generate sensible rankings using the $A Q R$ weighted averages may be to rescale all quality measurements to the same rate of occurrence, say per hundred. In the original AQR rankings, on-time arrivals were shown to be irrelevant. With rates per hundred, we have just the opposite result: airline rankings depend solely on on-time arrivals and everything else is irrelevant. The reason is that the rate of on-time arrivals per hundred is enormous compared to the other rates. See for example Table 2, which ranks America West and Southwest using 2002 DOT data and equal absolute weights. In the first comparison, DOT data in original rates are used in the AQR average (last column of the table) and Southwest receives the larger score. In the second comparison, DOT data are rescaled to rates per hundred and America West receives the larger score. 


\begin{tabular}{|c|c|c|c|c|c|c|c|c|}
\hline & \multirow[b]{2}{*}{ Rate } & \multicolumn{4}{|c|}{2002 DOT Statistics } & \multicolumn{2}{|c|}{ Dimensional Analysis } & \multirow[b]{2}{*}{$\begin{array}{c}\text { AQR } \\
\text { Average } \\
\end{array}$} \\
\hline & & $\begin{array}{l}\text { On-Time } \\
\text { Arrivals }\end{array}$ & $\begin{array}{c}\text { Denied } \\
\text { Boardings }\end{array}$ & $\begin{array}{c}\text { Mishandled } \\
\text { Baggage }\end{array}$ & $\begin{array}{l}\text { Customer } \\
\text { Complaints }\end{array}$ & $\begin{array}{c}\text { Value } \\
\text { Function }\end{array}$ & $\begin{array}{c}\text { Weighted } \\
\text { avg. of logs }\end{array}$ & \\
\hline America West & Original & 0.829 & 0.200 & 3.550 & 1.630 & 0.716 & -0.145 & -1.138 \\
\hline Southwest & & 0.826 & 1.090 & 3.520 & 0.330 & 0.652 & -0.186 & -1.029 \\
\hline Ratio & & & & & & 1.098 & 0.781 & 1.106 \\
\hline Difference & & & & & & 0.064 & 0.041 & -0.109 \\
\hline America West & Per 100 & 82.900 & 0.020 & 0.036 & 0.002 & $71,632,247$ & 7.855 & 20.711 \\
\hline Southwest & & 82.600 & 0.109 & 0.035 & 0.000 & $65,237,445$ & 7.814 & 20.614 \\
\hline Ratio & & & & & & 1.098 & 1.005 & 1.005 \\
\hline Difference & & & & & & $6,394,802$ & 0.041 & 0.097 \\
\hline Weight & & 1 & -1 & -1 & -1 & & & \\
\hline
\end{tabular}

Table 2. This table demonstrates the effects of changing the size of units of measurement in ranking a pair of airlines. In the first comparison, with original DOT statistics and equal absolute weights, the AQR average (last column) gives Southwest the larger score; in the second comparison, all statistics are rescaled to rates per hundred and the $A Q R$ reverses the rankings. In dimensional analysis, rankings are consistent. Scores in the value-function column are the products of quality measurements, with each raised to a power equal to its weight. Another dimensionally correct way to rank the airlines is to use the weighted average of logged quality measures. 
Precisely the same problem occurs in the AQR when all quality measurements are stated in any other common rate. What if the differences in magnitude are reduced by changing on-time arrivals to late arrivals, again with all measurements at the same rate? This idea is of no help because the rate of late arrivals becomes the only relevant measurement. Other examples could be presented but it should be obvious that many alternative AQR rankings can be generated by rescaling selected individual measurements to overwhelm the others.

As demonstrated in Table 2, these scaling problems do not exist in the value function derived from dimensional analysis. Using original DOT data with equal absolute weights, the value function gives overall quality scores of 0.716 for America West and 0.652 for Southwest. The scores have no particular numeric interpretation except to say that America West provides better quality than Southwest (under the given assumptions and weights). When we rescale the data to rates per hundred, overall scores grow dramatically but the important point is that the ratio of scores does not change. For any pair of airlines, the ratio of overall quality scores cannot change no matter how quality measurements are scaled, a result guaranteed by the condition of absolute significance of relative magnitude placed on the value function. It follows that overall quality rankings of any number of airlines cannot depend on the size of units of measure. 
The value function can produce rather unwieldy numbers as it did in the second comparison in Table 2. It may be more convenient to base rankings on the weighted averages of logarithms of quality measurements. The same conclusions hold except that in log-scale the difference between scores, rather than the ratio of scores, is unaffected by the size of units of measure.

Airline quality rankings from 1998 - 2002 are shown in Table 1. Anyone who wishes to reproduce the calculations should note that AQR weighted averages are computed monthly. At year end, for unstated reasons Bowen and Headley compute an unweighted average of monthly averages to obtain final rankings. For all data in Table 1, there is no significant difference in final AQR rankings regardless of whether an average of monthly averages or an average of final data for the year are used. The same comment is true for dimensional analysis. 


\section{Sensitivity analysis}

Table 3 examines the sensitivity of 2002 airline quality rankings to weights in the value function. Using original AQR weights, dimensional analysis ranks the top three airlines as America West, U.S. Airways, and American Eagle. The table shows how the top three airlines change using 24 combinations of weights as

follows: 1 and 2 for on-time arrivals, -1 and -2 for denied boardings and mishandled baggage, and $0,-1$, and -2 for customer complaints. The zero weight for customer complaints excludes this factor from the value function for reasons explained above.

Sensitivity analysis reveals that a group of five airlines (America West, U.S. Airways, American, American Eagle, and Southwest) dominated the industry in overall quality in 2002. The top three airlines were always chosen from this group and there appears to be no reasonable combination of weights that would have admitted any other airline to the top three. America West's performance was the most consistent or least sensitive to weights. America West ranked among the top three airlines in 22 cases, among the top two in 20 cases, and first in 13 cases. The most important conclusion from Table 3 is that exclusion of customer complaints made the rankings highly insensitive to weights on the remaining quality factors. Without customer complaints, America West and U.S. Airways always ranked first and second, respectively, with American in third place in six of eight cases. 


\begin{tabular}{|c|c|c|c|c|c|c|}
\hline \multicolumn{4}{|c|}{ Dimensional analysis weights } & \multicolumn{3}{|c|}{ Top 3 Airlines } \\
\hline On-Time & Denied & Mishandle & d Customer & & & \\
\hline Arrival \% & Boardings & Baggage & Complaints & 1 & 2 & $\underline{3}$ \\
\hline 8.63 & -8.03 & -7.92 & -7.17 & America West & US Airways & American Eagle \\
\hline 1 & -1 & -1 & 0 & America West & US Airways & American \\
\hline 1 & -1 & -1 & -1 & America West & US Airways & American Eagle \\
\hline 2 & -1 & -1 & 0 & America West & US Airways & American \\
\hline 2 & -1 & -1 & -1 & US Airways & America West & American Eagle \\
\hline 1 & -2 & -1 & 0 & America West & US Airways & American Eagle \\
\hline 1 & -2 & -1 & -1 & American Eagle & America West & US Airways \\
\hline 2 & -2 & -1 & 0 & America West & US Airways & American Eagle \\
\hline 2 & -2 & -1 & -1 & America West & American Eagle & US Airways \\
\hline 1 & -1 & -2 & 0 & America West & US Airways & American \\
\hline 1 & -1 & -2 & -1 & US Airways & America West & Southwest \\
\hline 2 & -1 & -2 & 0 & America West & US Airways & American \\
\hline 2 & -1 & -2 & -1 & US Airways & America West & Southwest \\
\hline 1 & -2 & -1 & -2 & American Eagle & America West & Southwest \\
\hline 2 & -2 & -1 & -2 & American Eagle & America West & US Airways \\
\hline 1 & -2 & -2 & -2 & American Eagle & America West & US Airways \\
\hline 2 & -2 & -2 & -2 & America West & US Airways & American Eagle \\
\hline 1 & -1 & -1 & -2 & Southwest & American Eagle & US Airways \\
\hline 2 & -1 & -1 & -2 & Southwest & American Eagle & US Airways \\
\hline 1 & -2 & -2 & 0 & America West & US Airways & American \\
\hline 1 & -2 & -2 & -1 & America West & US Airways & American Eagle \\
\hline 2 & -2 & -2 & 0 & America West & US Airways & American \\
\hline 2 & -2 & -2 & -1 & America West & US Airways & American \\
\hline 1 & -1 & -2 & -2 & Southwest & US Airways & America West \\
\hline 2 & -1 & -2 & -2 & Southwest & US Airways & America West \\
\hline
\end{tabular}

Table 3. This table shows the sensitivity of airline quality rankings based on dimensional analysis. If weights are restricted to 1 and 2 for on-time arrivals, -1 and -2 for denied boardings and mishandled baggage, and 0, -1, and -2 for customer complaints, there are 24 combinations. America West's performance was less sensitive to weights than its competitors. 


\section{Other quality rating systems}

One of the referees for this paper asked this question: Are the dimensional mistakes in the AQR unique or a general phenomenon? This is a difficult question to answer. I examined a non-random sample of 100 web sites containing quality ratings. Most were simple consumer opinion surveys but there were numerous multiple-criteria ratings that gave no details on how the ratings were computed. Rather than follow up on all of these, I decided to focus on the two bestknown quality critics, Consumers Union (publisher of Consumer Reports) and J. D. Power and Associates. Even though Consumers Union is a not-for-profit organization, a contact refused to answer questions about how any of their quality ratings are computed, stating that they wished to avoid arguments. In an attempt to get answers, I became a member of Consumers Union, which did nothing to improve the quality of its responses. In contrast, J. D. Power was extremely helpful and provided detailed explanations of the methodology for several of its famous automotive quality studies. The studies were designed to avoid dimensional problems and I could see no reason to take issue with the results. 


\section{Conclusions}

Dimensional analysis is always based on one elementary principle, that of dimensional homogeneity. Quantities may be added or subtracted only when they have the same dimensions. The AQR has violated this principle since 1991, producing indefensible airline rankings.

DOT airline quality data are limited in scope and open to criticism for a variety of reasons. However, the DOT publishes the only industry-wide data on airline quality and I expect that reports of quality rankings will continue to receive a great deal of attention. The point of this paper is that dimensional analysis provides the correct value function for quality rankings using criteria with different dimensions and varying relative importance. Anyone who disagrees with the rankings is free to make his or her own decisions about relevant data and weights to be used in the value function.

Dimensional analysis is simple, robust, and flexible, both in defining performance measures and in determining the numerical standards for evaluation. Furthermore, dimensional analysis can deal with both tangible and intangible decision criteria, so long as the numbers are ratio-scaled. In the context of physics, Langhaar (1951) went so far as to argue that dimensional analysis can produce at least a partial solution to nearly any problem. This may seem improbable in operations research, but certainly there are many opportunities for dimensional reasoning. For additional examples, see Naddor (1966). 


\section{Appendix}

The purpose of this appendix is to identify a quality value function that does not depend on units of measure. To simplify the analysis, only systems with four quality metrics are considered, but the results are easily generalized.

Let $\alpha_{1}, \beta_{1}, \gamma_{1}, \delta_{1}$ represent a set of quality metrics for an airline. Let $\alpha_{2}, \beta_{2}$, $\gamma_{2}, \delta_{2}$ represent the same metrics for an alternative airline. The relative value of the first airline's quality is described by the unknown function $f\left(\alpha_{1}, \beta_{1}, \gamma_{1}, \delta_{1}\right)$. Relative value for the second airline is described by $f\left(\alpha_{2}, \beta_{2}, \gamma_{2}, \delta_{2}\right)$. The choice of the value function $f$ is made on the basis of the following proposed axiom: The ratio $f\left(\alpha_{1}, \beta_{1}, \gamma_{1}, \delta_{1}\right) / f\left(\alpha_{2}, \beta_{2}, \gamma_{2}, \delta_{2}\right)$ shall not depend on the units in which any metric is stated.

To determine the form of the value function that satisfies this axiom, we follow Bridgman (1922). The basic approach is to analyze the effects of changing the size of the units of measure. First, make the units in which $\alpha$ is measured $1 /$ wth as large. Then the number measuring $\alpha$ will be $w$ times as large or w $\alpha$. In the same way, make the number measuring $\beta 1$ xth as large, so the measuring number becomes $\times \beta$. This process produces the following relation:

$$
\frac{f\left(\alpha_{1}, \beta_{1}, \gamma_{1}, \delta_{1}\right)}{f\left(\alpha_{2}, \beta_{2}, \gamma_{2}, \delta_{2}\right)}=\frac{f\left(w \alpha_{1}, x \beta_{1}, y \gamma_{1}, z \delta_{1}\right)}{f\left(w \alpha_{2}, x \beta_{2}, y \gamma_{2}, z \delta_{2}\right)}
$$

It is important to note that our axiom requires this relation to hold for all values of $\alpha_{1}, \beta_{1}, \gamma_{1}, \delta_{1}$, for all $\alpha_{2}, \beta_{2}, \gamma_{2}, \delta_{2}$, and for all $w, x, y, z$. 
To solve for the unknown function $\mathrm{f}$, rewrite as follows:

$$
f\left(w \alpha_{1}, x \beta_{1}, y \gamma_{1}, z \delta_{1}\right)=f\left(w \alpha_{2}, x \beta_{2}, y \gamma_{2}, z \delta_{2}\right) \times \frac{f\left(\alpha_{1}, \beta_{1}, \gamma_{1}, \delta_{1}\right)}{f\left(\alpha_{2}, \beta_{2}, \gamma_{2}, \delta_{2}\right)}
$$

Next, differentiate partially with respect to $w$. Let $f_{1}$ represent the partial derivative of the function with respect to the first argument. This yields the following:

$$
\alpha_{1} f_{1}\left(w \alpha_{1}, x \beta_{1}, y \gamma_{1}, z \delta_{1}\right)=\alpha_{2} f_{1}\left(w \alpha_{2}, x \beta_{2}, y \gamma_{2}, z \delta_{2}\right) \times \frac{f\left(\alpha_{1}, \beta_{1}, \gamma_{1}, \delta_{1}\right)}{f\left(\alpha_{2}, \beta_{2}, \gamma_{2}, \delta_{2}\right)}
$$

Now put $w, x, y, z$ all equal to 1 . This produces:

$$
\alpha_{1} \frac{f_{1}\left(\alpha_{1}, \beta_{1}, \gamma_{1}, \delta_{1}\right)}{f\left(\alpha_{1}, \beta_{1}, \gamma_{1}, \delta_{1}\right)}=\alpha_{2} \frac{f_{1}\left(\alpha_{1}, \beta_{1}, \gamma_{1}, \delta_{1}\right)}{f\left(\alpha_{2}, \beta_{2}, \gamma_{2}, \delta_{2}\right)}
$$

Equation [4] is to hold for all values of $\alpha_{1}, \beta_{1}, \gamma_{1}, \delta_{1}$ and $\alpha_{2}, \beta_{2}, \gamma_{2}, \delta_{2}$.

Hence, keeping $\alpha_{2}, \beta_{2}, \gamma_{2}, \delta_{2}$ constant and allowing $\alpha_{1}, \beta_{1}, \gamma_{1}, \delta_{1}$ to vary, we have

$$
\frac{\alpha}{f} \frac{\partial f}{\partial \alpha}=\text { Const }
$$

or

$$
\frac{1}{\mathrm{f}} \frac{\partial \mathrm{f}}{\partial \alpha}=\frac{\text { Const }}{\alpha}
$$

which integrates to $f=C_{1} \alpha^{\text {Const }}$. The factor $C_{1}$ is a function of the other parameters $\beta, \gamma, \delta$. 
Next, repeat the process above, differentiating partially with respect to $x, y$, $z$ in turn, and integrating. The final result reveals the required value function:

$$
f=C \alpha^{a} \beta^{b} \gamma^{c} \delta^{d}
$$

In [7], the exponents $\mathrm{a}, \mathrm{b}, \mathrm{c}, \mathrm{d}$ are weights. The coefficient $\mathrm{C}$ is almost always chosen to be unity. 


\section{References}

Bowen, Brent and Dean Headley. 2003. The Airline Quality Rating 2003. April, 2003, retrieved on May 1, 2003 from (www.wichita.edu/aqr2003).

Braglia, Marcello and Roberto Gabbrielli. 2000. Dimensional analysis for investment selection in industrial robots. International Journal of Production Research 38(18) 4843-4848.

Bridgman, P. W. 1922. Dimensional Analysis. Yale University Press, New Haven, CT.

Continental Airlines. 2003. Company Awards. Retrieved on May 1, 2003 from (www.continental.com/company/profile/)

Daganzo, C. F. 1987. The break-bulk role of terminals in many-to-many logistics networks. Operations Research 35(4) 543-555.

Ehrhardt, E. 1979. The power approximation for computing $(\mathrm{s}, \mathrm{S})$ inventory policies. Management Science 25(8) 777-786.

Ehrhardt, E., C. Mosier. 1984. A revision of the power approximation for computing $(\mathrm{s}, \mathrm{S})$ inventory policies. Management Science 30(5) 618-622. 
Epstein, L. Ivan. 1957. A proposed measure for determining the value of a system. Operations Research 5(2) 297-299.

Evans, James R. and William L. Lindsay. 2002. The Management and Control of Quality. Southwestern, Cincinnati, $\mathrm{OH}$.

Huntley, H. E. 1951. Dimensional Analysis. Rinehart and Company, New York, NY.

Langhaar, Henry L. 1951. Dimensional Analysis and Theory of Models. Wiley, New York, NY.

Li, C.C., Y.P. Fun, J.S. Hung. 1997. A new measure for supplier performance evaluation. IIE Transactions 29(2), 753-758.

Mahoney, J. F., J.A. Ventura. 1985. Dimensional analysis in an industrial engineering setting. IIE Transactions 17(2) 198-203.

Naddor, Eliezer. 1966. Dimensions in Operations Research. Operations Research 14(1) 508-514.

Silver, E.A. 1983. An example of indifference curves in inventory control. IIE Transactions 15(1) 79-80. 
Sivazlian, B.D. 1971. Dimensional and computational analysis in stationary $(\mathrm{s}, \mathrm{S})$ inventory problems with gamma-distributed demand. Management Science 17(6) 307-311.

Starr, Martin K. 1996. Operations Management: a Systems Approach. Boyd \& Fraser Publishing Company, Danvers, MA.

U.S. Department of Transportation. 2002. Reporting the Causes of Airline Delays and Cancellations (Docket No. OST 2000-8164, November 25, 2002), 67(227), 70535-70545,

U.S. Department of Transportation. 2003, Air Travel Consumer Reports, 1998-2002, retrieved on May 1, 2003, from (www.airconsumer.ost.dot.gov/reports/atcr02.htm)

Vignaux, G.A., Sudha Jain. 1988. An approximate inventory model based on dimensional analysis. Asia-Pacific Journal of Operational Research 5(2) 117123.

Willis, T. Hillman, C. Richard Huston, Frank Pohlkamp. 1993. Evaluation measures of just-in-time supplier performance. Production and Inventory Management Journal, 32(3) 1-6. 